\title{
Análise de causalidade entre crescimento econômico e desenvolvimento do mercado financeiro no Brasil
}

\author{
Larissa Kaoane F. Ribeiro*, Rosangela Ballini.
}

\section{Resumo}

A relação entre o desenvolvimento financeiro e o crescimento econômico se constitui em tema amplamente apresentado na literatura econômica, apesar disso, não existe consenso a respeito da direção da causalidade.O objetivo deste trabalho é analisar esta relação no Brasil no período de 2008 a 2015, a partir de testes de raíz unitária, teste de cointegração e análise da causalidade de Granger.

\section{Palavras-chave: \\ Crescimento econômico, desenvolvimento financeiro, teste de cointegração.}

\section{Introdução}

A importância do sistema financeiro para o crescimento econômico pode ser relacionada à decisão de investir, pois em um cenário de intermediação financeira bem desenvolvida, há uma maior oferta de crédito e diversificação de riscos, afetando positivamente as expectativas dos investidores e assim criando um ambiente propício para o investimento. Tendo em conta que este último é o principal determinante da acumulação de capital e, portanto, da capacidade produtiva, é possível inferir que há relação entre desenvolvimento financeiro e crescimento econômico. Embora existam evidências empíricas desta relação, não há um consenso sobre a direção da causalidade. Desta forma, esta pesquisa busca aprofundar a análise da relação entre desenvolvimento financeiro e crescimento econômico no Brasil, a partir de uma perspectiva econométrica.

\section{Resultados e Discussão}

Os dados utilizados para a realização dos testes de causalidade são mensais e cobrem o período de março de 2008 a dezembro de 2015. Para tanto, dois conjuntos de variáveis são utilizados: a) crescimento econômico, representado pela série do PIB em logaritmo (LPC) e b) indicadores de desenvolvimento financeiro, representados a seguir:

$$
\begin{aligned}
& \mathrm{LAM}=\log ((\mathrm{M} 2-\mathrm{PMPP}) / \mathrm{M} 2) \\
& \mathrm{LAP}=\log ((\mathrm{M} 2-\mathrm{PMPP}) / \mathrm{PIB}) \\
& \mathrm{LCT}=\log (\mathrm{SCC} / \mathrm{PIB})
\end{aligned}
$$

em que M2 é o agregado monetário amplo, PMPP é papelmoeda em poder do público e SCC é o saldo da carteira de crédito.

A partir disso, realizou-se testes de raiz unitária, de cointegração, ajuste de um modelo vetor auto-regressivo e análise de causalidade de Granger, cujos resultados são resumidos a seguir.

\section{- $\quad$ Teste de Raiz Unitária - Dick-Fuller Aumentado}

Tabela 1. Teste de Raiz Unitária

\begin{tabular}{l|r|r|c}
\hline Série & Estatística & p-valor & Decisão \\
\hline LAM & $-0,528$ & 0,4852 & Não rejeição \\
LAP & 1,342 & 0,9540 & Não rejeição \\
LCT & $-1,584$ & 0,4861 & Não rejeição \\
LPC & 0,849 & 0,8921 & Não rejeição \\
\hline
\end{tabular}

Hipótese nula: presença de raiz unitária.

Resultado: todas as séries são não-estacionárias.

\section{- Teste de Cointegração de Johansen}

Tabela 1. Teste de Cointegração

\begin{tabular}{c|l|r|r}
\hline Teste & $\mathrm{H}_{0}$ & Estatística & Valor crítico 5\% \\
\hline & $r=0$ & 75,808 & 47,856 \\
Traço & $r \leq 1$ & 29,680 & 29,797 \\
& $r \leq 2$ & 13,842 & 15,495 \\
& $r \leq 3$ & 2,620 & 3,841 \\
\hline & $r=0$ & 46,127 & 27,584 \\
Máximo & $r \leq 1$ & 15,838 & 21,131 \\
Autovalor & $r \leq 2$ & 11,221 & 14,264 \\
& $r \leq 3$ & 2,620 & 3,841 \\
\hline
\end{tabular}

Resultado: 1 vetor de cointegração.

- Verificação da adequação do modelo:

- Teste LM de autocorrelação dos resíduos: ausência de autocorrelação até a defasagem 12.

- Teste de normalidade: resíduos seguem distribuição normal.

- Exogeneidade: apenas LAP é fracamente exógena.

- Teste de causalidade de Granger: LAP é Granger-causada pelas demais variáveis do modelo.

\section{Conclusões}

Quando o desenvolvimento financeiro é representado por qualquer dos indicadores utilizados, temos que este causa o crescimento do produto per capita. Já no sentido contrário, as evidências não são tão consistentes, pois, foi verificado que produto per capita não causa variações na variável LAP individualmente, mas apenas em conjunto com as demais variáveis. Assim, os resultados mostraram que há evidências de que o desenvolvimento financeiro exerce efeitos positivos e de forma unidirecional sobre o crescimento da economia do Brasil, no período analisado.

\section{Agradecimentos}

À Prof. Drª . Rosangela Ballini pela orientação e ao CNPq pelo fomento concedido ao projeto.

\footnotetext{
1 MATOS, O. C. Desenvolvimento do sistema financeiro e crescimento econômico no Brasil: Evidência de causalidade. Brasília, DF: Banco Central do Brasil, Set. 2002. (Trabalho para Discussão, No. 49).
} 